Invited Articles

Pensar en Movimiento:

Revista de Ciencias del Ejercicio y la Salud ISSN 1659-4436

Vol. 16, No.2, pp. 1 - 20

Opening July 1, closing December 31, 2018

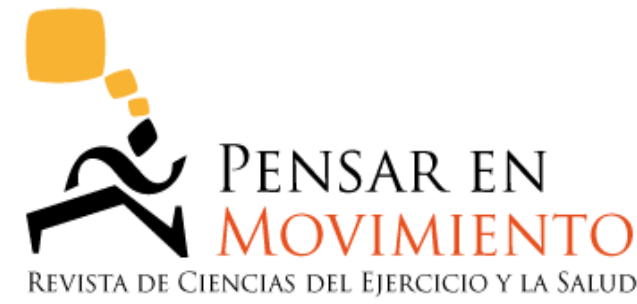

THE GLOBAL STATUS OF PHYSICAL ACTIVITY IN THE PREVENTION OF CHILDHOOD OBESITY ${ }^{1}$

\title{
ESTADO GENERAL DE LA ACTIVIDAD FÍSICA EN LA PREVENCIÓN DE LA OBESIDAD INFANTIL
}

\section{ESTADO GERAL DE ATIVIDADE FÍSICA NA PREVENÇÃO DA OBESIDADE INFANTIL}

\author{
Abigail Duffine Gilman, $P h D, R D N^{(C, D, E)} \&$ \\ Stella Lucia Volpe, PhD, RDN, ACSM-CEP, FACSM(C,D,E) \\ slv43@drexel.edu \\ Department of Nutrition Sciences, Drexel University, Philadelphia, PA USA \\ Original submission: 2017-08-11; resubmitted: 2018-03-21, 2018-07-10; \\ accepted: 2018-07-24; published: 2018-11-26.
}

Doi: https://doi.org/10.15517/pensarmov.v16i2.30143

\begin{abstract}
Duffine Gilman, A.E. \& Volpe, S.L. (2018). The global status of physical activity in the prevention of childhood obesity. Pensar en Movimiento: Revista de Ciencias del Ejercicio y la Salud, 16(2), 1-20. Childhood obesity is a public health concern that threatens the health and wellbeing of children worldwide and is associated with several of their chronic health conditions. Although a positive energy balance leads to excess body weight in children, there are several factors that influence their weight status. Dietary intake and physical activity greatly contribute to the energy balance in children. Mental health is also associated with their weight status and physical activity. Further, race and ethnicity, family structure, and the built environment
\end{abstract}

\footnotetext{
${ }^{1}$ Original submission in English. Also available in the Spanish-translated version in this journal
} 
contribute to the amount of physical activity achieved by children. One purpose of the current review is to summarize the connection between physical activity and weight status in children, and highlight key factors influencing this relationship, such as mental health and race, ethnicity, family structure and the built environment. Another purpose of this review is to highlight interventions and policies that may influence the relationship between physical activity and weight status in children. Policies that influence the surrounding environment may enhance children's accessibility for physical activity and affect neighborhood safety, the density of supermarkets and commercial physical activity facilities available, as well as the provision of structured physical activity opportunities for children. Policies that influence the school environment also provide the opportunity to facilitate additional physical activity for students. Therefore, the overall purpose of this review is to discuss the many factors that influence weight status in children and provide ideas for future research.

Keywords: Built Environment; Children; Obesity; Policy

\section{RESUMEN}

Duffine Gilman, A.E. \& Volpe, S.L. (2018). Estado general de la actividad física en la prevención de la obesidad infantil. Pensar en Movimiento: Revista de Ciencias del Ejercicio y la Salud, 16(2), 1-20. La obesidad infantil es una preocupación en materia de salud pública que amenaza la salud y el bienestar de los niños en todo el mundo y que se relaciona con varias condiciones crónicas de salud en ese grupo. Aunque el equilibrio energético positivo conlleve a un exceso de peso corporal en los niños, hay varios factores que influyen en su estado de peso. El consumo de alimentos y la actividad física contribuyen en gran medida al equilibrio energético de los niños. La salud mental también se relaciona con su estado de peso y actividad física. Además, la raza y el origen étnico, la estructura familiar, así como el ambiente construido contribuyen a la cantidad de actividad física que practican los niños. Uno de los objetivos de esta revisión es resumir la conexión entre la actividad física y el estado de peso en los niños y resaltar los factores clave que influyen en esta relación, tales como la salud mental y la raza, el origen étnico, la estructura familiar y el ambiente construido. Otro objetivo es resaltar las intervenciones y las políticas que pueden influir en la relación entre la actividad física y el estado de peso en los niños. Las políticas que influyen en el entorno pueden mejorar la accesibilidad a actividades físicas por parte de los niños y afectar la seguridad, la densidad de los supermercados y las instalaciones comerciales de actividad física disponibles en los vecindarios, y el suministro de oportunidades estructuradas de actividad física para los niños. Las políticas que influyen en el entorno escolar también brindan oportunidades para facilitar la actividad física adicional en los niños. Por lo tanto, el propósito general de esta revisión es estudiar los muchos factores que influyen en el estado de peso de los niños y proporcionar ideas para futuras investigaciones.

Palabras clave: Ambiente construido; Niños; Obesidad; Políticas 


\section{RESUMO}

Duffine Gilman, A.E. \& Volpe, S.L. (2018). Estado geral de atividade física na prevenção da obesidade infantil. Pensar en Movimiento: Revista de Ciencias del Ejercicio y la Salud, 16(2), 1-20. A obesidade infantil é uma preocupação de saúde pública que ameaça a saúde e o bem-estar de crianças em todo o mundo e está relacionada com várias condições crônicas de saúde nesse grupo. Embora o equilíbrio energético positivo signifique o excesso de peso corporal em crianças, existem vários fatores que influenciam seu estado de peso. O consumo de alimentos e a atividade física contribuem em grande parte no equilíbrio energético das crianças. A saúde mental também está relacionada com seu estado de peso e a atividade física. Além disso, raça e etnia, estrutura familiar, bem como o ambiente construído contribuem para a quantidade de atividade física praticada pelas crianças. Um dos objetivos desta revisão é resumir a conexão entre atividade física e estado de peso nas crianças e destacar os principais fatores-chave que influenciam essa relação, como saúde mental e raça, origem étnica, estrutura familiar e o contexto construído. Outro objetivo é destacar as intervenções e políticas que podem pesar na relação entre a atividade física e o peso nas crianças. As políticas que influenciam o contexto podem melhorar a acessibilidade às atividades físicas por crianças e afetar a segurança, a densidade de supermercados e instalações comerciais de atividades físicas disponíveis na vizinhança e a oferta de oportunidades estruturadas de atividades físicas para as crianças. As políticas que influenciam o contexto escolar também oferecem oportunidades para facilitar a atividade física adicional para os alunos. Portanto, o propósito geral desta revisão é estudar os muitos fatores que influenciam o estado de peso das crianças e fornecer ideias para pesquisas futuras.

Palavras-chave: Ambiente construído, Crianças, Obesidade, Políticas

Childhood obesity is a major public health concern worldwide, and its prevalence is on the rise. For example, in the United States, obesity affects nearly $17 \%$ of children (Ogden, Carroll, \& Flegal, 2014). In Costa Rica, 14\% of school children, 6 to 12 years of age, are considered obese (Ministerio de Educación Pública, 2017). These alarming rates of childhood obesity in the developed world indicate that there may be a disturbance in the energy balance of children: an increase in energy consumed paired with a decrease in energy expended. Although not the only influence, the lack of physical activity often creates the positive energy balance in children beyond that needed for normal growth and development. Excessive positive energy balance increases the risk of obesity in childhood.

Obesity in childhood increases the risks of developing chronic disease later in life, including cardiovascular and liver diseases, certain types of cancer, type 2 diabetes mellitus, and social repercussions associated with the condition (Baker, Olsen, \& Sorensen, 2007; Liang et al., 2015; Marietti \& Bugianesi, 2016; Stevens, Herbozo, Morrell, Schaefer, \& Thompson, 2016). Although the rates of childhood overweight and obesity may be plateauing in some

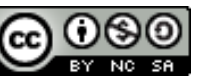

This work is licensed under a Attribution-NonCommercial-ShareAlike 4.0 International (CC BY-NC-SA 4.0) 
regions of the world, such as the United States (Ogden, Carroll, Kit, \& Flegal, 2014), the global rising prevalence remains a concern for public health initiatives because of the overall influence obesity has on the younger population.

Obesity is a result of a positive energy balance; however, this oversimplified model fails to acknowledge the plethora of factors that affect an individual in his or her food and beverage intake choices, as well as the factors that influence engagement in physical activity. In this review, we will focus primarily on physical activity and how it affects, and is affected by, childhood obesity. The aims of the current literature review are:

a) To summarize the connection between physical activity and weight status in children, and highlight key factors influencing this relationship.

b) To highlight interventions and policy actions that may influence the relationship between physical activity and weight status in children.

\section{Overview of Physical Activity and Obesity}

Understanding energy balance is paramount to comprehend the relationship between physical activity and weight status. In other words, energy balance describes the relationship among energy intake through food and beverages, and energy expenditure via physical activity and metabolic processes within the body (Hill, Wyatt, \& Peters, 2012). When energy intake equals energy expended, the body is in energy balance and weight status is stable. However, if one side of the equation surpasses the other, weight loss (negative energy balance) or weight gain (positive energy balance) may occur. Regulating this dynamic equation is multi-faceted with many internal and external forces interacting to achieve balance.

In the Freiburg Intervention Trial for Obese Children (FITOC), Kreuser, KromeyerHauschild, Golhofer, Korsten-Reck \& Rottger (2013) examined the distribution of time spent in sedentary behavior and physical activity between 8 to 11-year-old children, who were overweight and healthy weight using accelerometry. Children enrolled in the study lived in the same city in the south of Germany and attended local elementary schools. An algorithm was used to determine the level of activity children completed while wearing the accelerometer. The researchers classified the amount of time children wore the accelerometers into active time, which included physical activity, and passive time, which included no physical activity. The amount of time spent in "passive" behavior, that is lacking any physical activity, was significantly higher in children who were overweight, while children of healthy weight were more "active". This pattern of physical activity time may indicate that a more active lifestyle, which includes physical activity, may contribute to a neutral, or even a negative, energy balance, contributing to an overall healthy weight.

The overwhelming prevalence of childhood obesity directs researchers to focus their attention toward the controllable aspects of energy balance: energy intake and energy expenditure. By addressing the current status of physical activity among children, researchers may apply meaningful interventions to manipulate the energy balance equation to lower the prevalence of childhood obesity (Hill et al., 2012).

$$
-4 \text { - }
$$

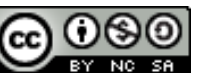

This work is licensed under a 
Physical Activity and Sedentary Behavior Recommendations. The World Health Organization (WHO) recommends that children 5 to 17 years of age engage in at least 60 minutes of moderate-to-vigorous physical activity (MVPA) per day (World Health Organization, 2010). Intensity of exercise is determined by the Metabolic Equivalent Units (METs) expended by an activity. A moderate intense activity, such as brisk walking, bicycling, or playing doubles tennis, expends approximately 3.0 to 6.0 METs (approximately 10.5 to 21 milliliters of oxygen per kilogram of activity per minute $[\mathrm{mL} / \mathrm{kg} / \mathrm{min}])$. Vigorous activities may include: jogging, shoveling snow, playing basketball or soccer (Ainsworth et al., 2000). However, measuring the METs expended on a daily basis in children is not common practice, and children are recommended to engage in activities that make them work hard and get out of breath (Brener, Kann, Shanklin, Kinchen, Eaton, Hawkins \& Flint, 2013). The WHO recommendations are applicable for all children regardless of sex, race, ethnicity or income level, and include recommendations for those with disabilities. Children with disabilities are encouraged to work with their health care providers to facilitate the appropriate amount of physical activity tolerable for their individual disability. The recommendations also encourage children who are currently inactive to progressively increase physical activity through adjustments of duration, frequency and intensity of activity over time (World Health Organization, 2010).

Although the WHO does not have specific guidelines for sedentary behavior, individual countries have guidelines for sedentary behavior time and associated behaviors. For example, the United States Department of Health and Human Services (USDHHS) recommends that children limit screen time, which encourages sedentary behaviors and takes away from physically active time (U.S. Department of Health and Human Services, 2008). Similarly, the Canadian Society for Exercise Physiology (CSEP) provides recommendations for sleep and sitting, as well as physical activity. These guidelines recommend that children, between 5 and 13 years of age, obtain nine to eleven hours of sleep per night. Children 14 to 17 years of age should obtain eight to ten hours of sleep per night. They also recommend that children sit for no more than two hours per day (Canadian Society for Exercise Physiology, 2016). Although recommendations direct children to engage in physical activity and limit sedentary behavior, many children still do not meet the recommended physical activity guidelines. Hallal et al. (2012) conducted an international survey of children, 13 to 15 years of age, from 122 countries. They reported that nearly $70 \%$ of participants failed to meet the WHO physical activity recommendations (Hallal et al., 2012). This alarming proportion of children not meeting the recommendations should further influence researchers to continue investigating the barriers to physical activity in children.

Physical Activity and Weight Status. Physical activity is often a good marker of weight status in children. Kreuser et al. (2013) used a mixed-methods model to evaluate the amount of physical activity achieved by German children enrolled in the Freiburg Intervention Trial for obese Children based on their weight status. They identified that children who were overweight were significantly $(p<0.001)$ less active than children who were not overweight. Children who were not overweight obtained 510 minutes (8.5 hours) of active time per weekday, whereas 
overweight children completed 440 minutes (7.3 hours) of active time per weekday (Kreuser et al., 2013). However, although children who were overweight were less active on the weekdays compared to children who were not overweight, the children who were overweight were more active on the weekends. On the other hand, children who were not overweight exhibited a significant $(p<0.001)$ decrease in active minutes from the weekdays to the weekends. This discrepancy in activity levels may be a valuable entry point for meaningful physical activity interventions.

Deforche, De Bourdeaudhuij, D'Hondt \& Cardon (2009) reported similar results in a crosssectional study of Flemish children in which they measured physical activity and body mass index (BMI) z-score in children, 6 to 10 years of age. Body mass index is an equation that relates the weight of an individual in kilograms $(\mathrm{kg})$ to the individual's height in meters $(\mathrm{m})$ squared, providing a value in $\mathrm{kg} / \mathrm{m}^{2}$. The BMl z-score is a standardized BMI value based on children of the same sex and age, which indicates the number of standard deviations an individual is from the mean BMI value. Using data collection from accelerometry and parental physical activity questionnaires, the researchers determined that children who were not overweight, determined by a BMI z-score less than 1, spent, on average, 20 minutes per day more time in MVPA compared to children who were overweight (Deforche et al., 2009). Deforche et al. (2009) did not report differences between weekday and weekend activity levels.

Physical Activity, Mental Health and Cognition. A child's weight status and physical activity are also associated with a child's self-worth and health-related quality of life (HRQLL) (de Beer et al., 2007; Schwimmer, Burwinkle, \& Varni, 2003; Wafa et al., 2016). Health-related quality of life is a multi-dimensional concept related to physical, mental, emotional, and social functioning. It provides an assessment of the effect that health status has on quality of life (Office of Disease Prevention and Health Promotion, 2016). To further understand the association of physical activity and HRQoL, Schwimmer et al. (2003) examined the results of a pediatric quality of life survey tool provided to children, 5 to 18 years of age, referred to the Children's Hospital and Health Center of San Diego, California. The obese children recruited to the study had a mean BMI of $34.7 \mathrm{~kg} / \mathrm{m} 2$ (Standard Deviation [SD] \pm 9.3 ), and a BMI Z-Score of $2.6(S D \pm 0.5)$. The researchers compared the results to inventory reference data and reported that the children and adolescents with obesity, defined by BMI greater than the 95th percentile, had a significantly $(p<0.001)$ lower HRQoL compared to children and adolescents with a healthy body weight (Schwimmer et al., 2003). Additionally, the children with obesity had a 5.5 times greater likelihood of having a decreased HRQoL compared to those children of a healthy body weight (Schwimmer et al., 2003). Although these results are cross-sectional by design, similar associations were identified by Rank et al. (2014) when assessing the HRQoL change following an inpatient weight-loss program. Rank et al. (2014) assessed longitudinal changes in HRQoL, as well as BMI, physical activity, and sedentary behavior of children and adolescents, 7 to 20 years of age, who had completed an inpatient weight-loss treatment program in Berchtesgaden, Germany. Measurements were taken at baseline, upon completion of the inpatient weight-loss program, as well as at 6,12 and 24 months after the start of the program. At 24 months, participants had significantly $(p<0.001)$ improved overall HRQoL compared to baseline -6 - 
measurements, with the greatest gains seen in the self-esteem domain of HRQoL. The researchers also reported that the change in HRQoL was positively associated with physical activity levels; an increased change in physical activity level explained $30 \%$ of the variation in overall HRQoL $(p<0.05)$ (Rank et al., 2014). However, it is important to note that these changes were most influential during the children's time spent in the inpatient setting. Regardless, the significant effects of increased physical activity on HRQoL remained at 24 months after completion of the study. These long lasting effects of increased physical actvitiy indicate that, while the inpatient setting may have been important and influential for these children, the residual effects of increased physical activity on HRQoL may be beneficial for all children outside of the inpatient setting, and may include those who do not require inpatient weight management programs. The beneficial response of increasing physical activity on improving HRQoL may translate to the general population of children who are overweight or obese. Additionally, successfully identifying the relationship between levels of physical activity and improvements in HRQoL provide promise for targeted physical activity interventions for all overweight or obese children.

Beyond improving $\mathrm{HRQoL}$, evidence suggests that physical activity may also affect children's cognitive function and ability to learn. In a randomized controlled trial, Davis et al. (2011) evaluated how exercise affected executive function and mathematical achievement in children, 7 to 11 years of age, who were both overweight and sedentary. The researchers used blinded, standardized psychological evaluations to assess cognition and academic achievement, as well as functional magnetic resonance imaging (fMRI) to assess brain activity following exercise (C. L. Davis et al., 2011). Executive function is a mental process that enables children to plan, focus and delay distraction. An improved executive function in children helps them regulate behaviors and succeed in elementary school (Eigsti et al., 2006). The children were randomized into three groups: 20 minutes, 40 minutes or no minutes of regular afterschool aerobic exercise for three months. The researchers reported a significant dose-response benefit to the exercise protocol on both executive function $(p=0.013)$ and mathematics achievement $(p=0.045)$. The $\mathrm{fMRI}$ also showed increased activity in brain regions controlling executive function (C. L. Davis et al., 2011). Although academic performance is not a true health benefit, the improved cognition of children associated with increased physical activity may enhance the academic achievements of children as well (Kreuser et al., 2013).

Obesity in childhood is multifaceted and a result of several interactions that can affect the weight status of children. It is difficult to pinpoint just one influence that determines a child's weight status; nonetheless, physical activity can greatly contribute to the weight status, health and overall well-being in children. While physical activity is identified as a crucial component in maintaining a healthy body weight throughout childhood and adolescence, many children, especially those who are overweight and obese, do not achieve the recommended amount of daily physical activity. Focusing research and implementing programming to encourage increased physical activity at younger ages can improve the current health status of children and establish lifelong patterns of physical activity. While this review has focused on the associations of physical activity in children, the remainder of this review will highlight some of the influences driving the amount of physical activity achieved in children.

- 7 -

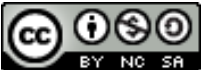

This work is licensed under a

Attribution-NonCommercial-ShareAlike 4.0 International (CC BY-NC-SA 4.0) 


\section{Factors Influencing Physical Activity in Children}

The lack of physical activity in children is apparent; however, the causes influencing physical inactivity are numerous and multifaceted. In the following section, we will discuss the multitude of factors contributing to physical activity engagement in children and actions to be taken that may improve the status of activity in children.

Racial and Ethnic Influences. Race and ethnicity influence physical activity and the prevalence of obesity in children. Researchers throughout the world indicate that differences exist with respect to race and ethnicity in the amount of physical activity in which children participate. Cross-sectional analyses of data from the 2009 to 2010 United States National Health and Nutrition Examination Survey (NHANES) indicated that Hispanic children in the United States are less likely (adjusted Odds Ratio of 0.6 (95\% Confidence Interval [Cl], 1.18, 2.43) to meet physical activity recommendations than non-Hispanic white children (Fakhouri, Hughes, Brody, Kit, \& Ogden, 2013). However, this phenomenon is not unique to the United States. Owen et al. (2009) conducted a large national study in the United Kingdom and reported racial differences in meeting recommendations for physical activity. Nearly 3,500 children, 9 to 10 years of age, enrolled in the Child Heart and Health Study in England (CHASE), wore accelerometers to quantify the amount of daily physical activity completed. The enrolled children identified their race as either White European, South Asian, or Black African-Caribbean living in England. The researchers reported that a significantly lower $(p<0.001)$ proportion of South Asians achieved the recommended 60 minutes of MVPA compared to White European children and Black African-Caribbean children. In addition, the South Asian children recorded nearly 900 fewer steps compared to their White European counterparts (Owen et al., 2009). While race and ethnicity do not dictate the amount of physical activity a child may achieve, the notable differences in physical activity achievements among racial and ethnic backgrounds allow for targeted physical activity interventions to those with increased need for improvements.

Family Structure and Dynamic. The structure and dynamics of a family unit can also predict and predispose children to engaging in physical activity. The support of a dual-parent home may encourage children to remain active. A single-parent home, on the other hand, may result in less physical activity in children. Puglisi, Okely, Pearson \& Vialle (2010) used a qualitative study design to investigate the barriers to physical activity in Australian children living with obesity, 5 to 12 years of age, through focus groups and interviews. Although many themes emerged from the interviews, family dynamics was identified as a strong barrier to physical activity. The participants acknowledged that families with single-parent homes introduced a barrier to physical activity, due in part to differing rules in each home, limited time, and inability to share parental responsibilities (Puglisi et al., 2010). The results of this study are strengthened through the work of Moore, Robinson, Rachel \& Boss (2014), who also highlighted the family structure as an important component of the physical activity equation (Moore et al., 2014). The researchers sought to identify barriers to a healthy lifestyle in a Mississippi elementary school, a

- 8 -

This work is licensed under a

Attribution-NonCommercial-ShareAlike 4.0 International (CC BY-NC-SA 4.0) 
state within the United States of America, with high rates of childhood obesity. Using the Barriers to Physical Activity Scale, a 21-item Likert-scale instrument to measure students' total level of perceived barriers to engage in physical activity, the researchers reported that singleparent compared to dual-parent/guardian households were determined to be a significant predictor of high versus low total barrier scores. The children in single-parent households had increased odds (Odds Ratio $=0.268,95 \% \mathrm{Cl}$ : $1.004,7.134$ ) of reporting more perceived barriers to physical activity compared to their dual-parent/guardian counterparts (Moore et al., 2014). Family dynamics, therefore, appear to influence the perceived barriers to engagement in physical activity among children.

Screen Time and Sleep Duration. Sedentary activities are those during waking hours that elicit a metabolic rate of 1.0 to 1.5 in metabolic equivalents (METS) according to the Compendium of Physical Activities (Ainsworth et al., 2000; Pate, O'Neill, \& Lobelo, 2008). The Sedentary Behavior Research Network (2017) added position to the definition to help qualify the term: behavior that elicits metabolism less than or equal to 1.5 METS in a seated or reclined position (Scott, Tyton \& Horswill, 2016). Sedentary behavior can be classified by a variety of specific behaviors including reading, playing quietly, watching television, using the computer or other electronic devices, and/or playing video games. Screen time, in particular, usually involves the combination of watching television, using the computer or other electronic devices, and/or playing video games (LeBlanc et al., 2012). Focusing on screen time, in particular, and not overall sedentary behavior time, can provide further information to understand how children devote their non-active time. LeBlanc et al. (2015) evaluated the amount of sedentary behavior time and screen time in children, 9 to 11 years of age, in 12 countries ( $n=5844)$ who participated in the International Study of Childhood Obesity, Lifestyle and the Environment (ISCOLE) program (LeBlanc et al., 2015). They reported that 54\% of the children represented failed to meet screen time guidelines of less than two hours per day. They also reported that boys were more likely than girls to exceed the two-hour limit. Higher screen time in children was found to be correlated with having a television or computer in the bedroom, poor weight status, and not meeting physical activity guidelines (LeBlanc et al., 2015). Similar findings were also shown when including the association of sleep duration for children. Sleep guidelines from the United States National Sleep Foundation recommend children, 6 to 13 years of age, obtain at least nine hours of sleep per night (National Foundation of Sleep, 2018). Laurson, Lee, Gentile, Walsh \& Eisenmann (2014) reported a protective effect of sleep duration in meeting all guidelines concerning screen time, physical activity and sleep duration. The researchers noted that $53 \%$ of boys and $42.5 \%$ of girls who did not achieve any of the recommended guidelines were overweight or obese, whereas only $16 \%$ of boys and $9 \%$ of girls who achieved all the recommendations were overweight or obese. They also reported that the odds of obesity decreased with each guideline met. Those children who failed to meet one, two or all three of the recommendations were 2.5, 4.5 and 8 times, respectively, more likely to be obese compared to those children who met all recommendations (Laurson et al., 2014). Although these findings indicate that children who spent more time sleeping also spent less time being physically active,

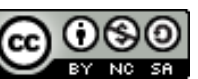

This work is licensed under a 
further research should focus on how each sedentary behavior individually and collectively affects obesity status.

The amount of screen time a child reports is often mediated by the access to television and/or a computer within the bedroom. Puglisi et al. (2010) reported that parents believe that having a television in the bedroom provides a barrier to physical activity and allows sedentary behavior to be the easy, and most frequently chosen option (Puglisi et al., 2010). To substantiate these beliefs, Atkin, Corder, \& van Sluijis (2013) sought to objectively identify sedentary behavior time in children who had televisions and computers in their bedrooms compared to those who did not. The researchers reported that, over four years, televisions in the bedrooms decreased, while the presence of computers in the bedroom rose. Though both televisions and computers facilitated an increase in overall screen time, an association with the increased screen time and total sedentary behavior time was not reported (Atkin et al., 2013). These results, however, were dissimilar to those reported by Ferrari et al (2015). The researchers analyzed data from the aforementioned multi-national ISCOLE study, focusing primarily on the data collected in Sāo Paulo, Brazil. They reported that girls with televisions in their bedrooms did, in fact, perform less MVPA compared to girls without televisions in their bedrooms. They also reported that MVPA was higher, and BMI lower in children with no electronic equipment in the bedroom (Ferrari et al., 2015). Although these results are equivocal in nature, they warrant further investigation into the relationship between screen time and overall physical activity.

The Built Environment: Urban and Rural Influences. Neighborhoods and the built environment are unmodifiable factors that play an influential role in the accessibility and safety of physical activity for children. Obesity disproportionately affects children based on their living situation. Davis et al. (2011) evaluated the 2003 to 2004 and 2005 to 2006 NHANES to determine the incidence of obesity among children, 2 to 18 years of age, living in urban communities in the United States, compared to those living in rural communities. The researchers reported that there were significantly $(p<0.05)$ more children living in rural areas who were obese compared to their urban counterparts. Upon further investigation, the researchers also identified that, although the weight status was significantly different between the children living in urban versus rural areas, there were no significant differences between health behaviors, including levels of physical activity, of the urban and rural children (Davis et al., 2011). This finding suggests that physical activity alone may not be the sole contributor to the obesity status of these children. Further consideration must be focused on other contributing factors, such as dietary intake. However, in a similar analysis of United States NHANES data collected in more than 14,000 children, from 1999 through 2006, Liu et al. (2012) also reported a significantly higher $(p<0.05)$ prevalence of overweight and obesity in children, 2 to 11 years of age. More children living in rural areas were overweight or obese (35.4\%), compared to children living in urban areas (29.3\%). The researchers also reported that $20.3 \%$ of rural children were inactive compared to $26.2 \%$ of urban children $(p<0.05)$. The mismatch in the prevalence of obesity and physical activity levels among rural and urban children should therefore incite further investigations into the disparities of weight status, including both physical activity levels -10 - 
and dietary intake. However, by identifying when, where and what kind of physical activity in which children are engaging may provide a better understanding of how these disparities exist.

The Built Environment: Neighborhood Access, Safety and Walkability. The built environment provides both opportunities and barriers for children to engage in physical activity. It comprises the buildings, roads, open spaces and sidewalks of a neighborhood, and influences an individual's perception of and acceptability of physical activity within the neighborhood (Sallis, Floyd, Rodriguez, \& Saelens, 2012). Tappe, Glanz, Sallis, Zhou \& Saelens (2013) examined the association between parental reports of the neighborhood environment and children's activity within the neighborhood, using both parent reports of physical activity and the use of data collected from accelerometers worn by children. The researchers analyzed baseline data from the Neighborhood Impact on Kids (NIK) Study, a National Institutes of Health (NIH)funded longitudinal, observational cohort study in the United States. Tappe et al. (2013) showed that parent-reported proximity to play areas was positively correlated with accelerometry recorded MVPA in children (Tappe et al., 2013).

The built environment and neighborhood structure are also influenced by safety and crime within the neighborhood, both of which play an important role for children and their parents when engaging in physical activity in the neighborhood (Roberts, Knight, Ray, \& Saelens, 2016; Sallis et al., 2012). The perception of crime in a neighborhood, outside of actual crime rates, independently mediates the physical activity of children (Janssen, 2014). In a cross-sectional analysis of 14,125 children, 11 to 15 years of age, Janssen (2014) explored the relationship between crime against people and physical activity outside of school in Canada. When controlling for crime and other confounders, such as sex, race, and number of parents in the household, the odds ratio of being physically active was $0.52(95 \% \mathrm{Cl}: 0.44$ to 0.62$)$ in children whose perception of neighborhood safety was in the lowest quintile. Conversely, the odds ratio of physical activity was 0.75 (95\% Cl: 0.60 to 0.95$)$ for children from neighborhoods with actual, not perceived, crime in the highest quintile. These results show that the perceptions of safety and crime are independently associated with physical activity outside of school in children (Janssen, 2014).

Although the perception of safety is influential on the amount of physical activity in children's neighborhoods, actual crime levels also influence physical activity engagement in children. Crime levels are particularly influential on the success of interventions aimed at increasing physical activity. In a pilot study based in Louisiana, United States, Newton et al. (2014) recruited the parents of inactive children, 6 to 10 years of age, for a targeted mobile phone-based intervention to increase children's daily steps. Children were randomly assigned to either an intensive intervention group or a minimal intervention group. The researchers reported a significant $(p<0.001)$ increase above baseline in total daily steps for both intensive intervention and minimal intervention groups, 2833 steps and 1428 steps, respectively (Newton et al., 2014). However, Broyles et al. (2016) conducted a follow-up study to further investigate the influence of crime rates on the effect of the pilot interventions and reported that neighborhood crime did, in fact, affect the intervention response. The researchers analyzed crime rates as a covariate of the intervention and showed that the intervention was effective in increasing daily steps only for 
those children located in low-crime neighborhoods $(p=0.008)$. The high-crime neighborhoods hindered the intervention response for both the intensive intervention and minimal intervention groups (Broyles et al., 2016). The results of these studies show how crime rates, and the perception of crime in the neighborhood, can mediate the daily physical activity in children, such that high-crime neighborhoods are prohibitive in fostering an environment of increased physical activity.

Physical and Policy Change Targeting the Built Environment. The built environment includes buildings, roads, open spaces and sidewalks of a neighborhood and influences an individual's perception and acceptability of physical activity within the neighborhood (Sallis et al., 2012). Disparities in neighborhoods can either support or hinder physical activity in children. Using logistic regression, Boone-Heinonen et al. (2013) reported that an increase in the density of neighborhood supermarkets and commercial physical activity facilities was associated with a decreased BMI in adults (Boone-Heinonen et al., 2013). However, this decrease in BMI affected men more than women. They also reported that the individuals with increased income had better access to public physical activity facilities (Boone-Heinonen et al., 2013). Although this report indicates an improved health benefit of developed neighborhoods for adults, understanding the association between neighborhood growth and weight status can direct policies and interventions that bolster neighborhood accessibility for improved health in the total population, including children.

Focusing on policy changes to improve the status of the built environment may subsequently improve the physical activity outcomes for children. Policy, therefore, should focus on improving access for those in greatest need. Subsidizing use of publicly funded recreation centers and physical activity resources for those with lower income, and creating incentives for women and girls to engage in physical activity may improve health outcomes and decrease disparities (Boone-Heinonen et al., 2013). Therefore, the creation of policies that incentivize use of public physical activity facilities and support behavior changes for higher-risk populations may improve the physical activity and ultimately the health of these at-risk populations (BooneHeinonen et al., 2013; Kreuser et al., 2013).

Additionally, creating programs and policies aimed at increasing physical activity can lessen access and usage disparities between neighborhoods, particularly for children (Watson, Harris, Carlson, Dorn, \& Fulton, 2016). In a United States Department of Health and Human Services weekly report, Watson et al. (2016) identified key changes to the built environment to improve the physical activity levels of children. The researchers then made recommendations for improvement, which included: increasing the safety and availability of sidewalks and locating nearby parks and recreation facilities. These targeted approaches aimed at improving the safety and access for physical activity opportunities in the neighborhood may increase the amount of time children spend being physically active. Researchers in Germany studied the neighborhood effect on children's physical activity (Kreuser et al., 2013). The researchers reported that families of low income, in particular, were less likely to engage in organized sports for physical activity. They reported that activity supported by public health initiatives, especially through social and sport organizations, was needed to facilitate easier accessibility of youth participation 
in sports. They also suggested that a wide range of offerings, in all kinds of sports, should be the first step in decreasing the high threshold for overweight children to take part in organized sports (Kreuser et al., 2013). This may also allow opportunities for children and their parents to develop their own ideas and activities for increasing physical activity. Many parents and children find identifying strategies for increasing participation in physical activity and reducing sedentary behaviors a challenge (Puglisi et al., 2010). Providing structured activities, motivations and suggestions for meeting the physical activity recommendations may provide the guidance necessary for success.

School Environment. Although the neighborhood and home environment are important aspects of children's physical activity patterns, school also provides an important tool for engaging children in physical activity. Children spend nearly half of their waking hours in the school setting, further highlighting the importance schools can have on activity levels. However, with increasing academic demands and limited organized physical activity engagement, the sedentary behavior time in which children engage within school hours may be detrimental to their health. Abbott, Straker, \& Mathiassen (2013) used data obtained from accelerometry to determine the amount of physically active and sedentary behavior time children had both in and out of schools. They reported that children engaged in significantly more $(p<0.001)$ sedentary behaviors during school hours, $66.8 \%$ of the time, compared to non-school hours, $62.4 \%$ of the time. Children also spent more uninterrupted sedentary behavior time (greater than 30 minutes) while at school compared to non-school time $(p<0.001)$ (Abbott et al., 2013). Although their findings did not reveal a difference between weekday and weekend activity levels, the findings highlight the need for children to be more active during school hours.

There are many factors that may be influencing levels of sedentary behavior time and physical activity time for children within school hours. Identifying which factors are most prohibitive to increasing physical activity can help policy makers, researchers and school administrators in making effective changes. Huberty, Dinkel, Coleman, Beighle, \& Apenteng (2012) conducted qualitative focus groups in the Midwest of the United States, with key informants in 12 elementary schools, to further investigate the causes contributing to the reduction in activity levels during the school day. These key informants included individuals who were significant school stakeholders related to children's physical activity, such as physical education teachers, supervisors, and volunteers. Overwhelmingly, focus group participants thought that physical activity was important and indicated several key factors affecting children's ability to be more active. These key factors included: increased academic demands, limiting time for physical activity; peer pressure, especially in girls, to not be active; and lack of space and equipment for engaging in physical activity (Huberty et al., 2012). The aforementioned themes are further reiterated in several systematic reviews addressing the school environment and physical activity (Dobbins, Husson, DeCorby, \& LaRocca, 2013; Harrison \& Jones, 2012; Morton, Atkin, Corder, Suhrcke, \& van Sluijs, 2016).

Changes to the School Environment. Changes to the school environment can also foster increasing physical activity in children; however, not all school-based changes translate to 
improved physical activity. Hunter, Leatherdale, Storey, \& Carson (2016) assessed the changes in school environment for nearly 19,000 high school children from 86 Canadian schools participating in the Cohort for Obesity, Marijuana use, Physical activity, Alcohol use, Smoking and Sedentary behavior (COMPASS), an ongoing quasi-experimental study in which the researchers collect annual data on multiple health behaviors. The researchers evaluated changes made in the participating schools and discovered that physical activity-related changes were associated with a significant increase in student MVPA. In particular, of the 61 schools that included physical activity changes, four of the schools' changes resulted in significant increases in MVPA. The changes that led to increased MVPA included: allowing the fitness center to be open during lunch $(\beta=17.1765,95 \% \mathrm{Cl}: 2.6079$ to 31.7451$)$; creation of an "Out and About" club focusing on health and wellness ( $\beta=17.7959,95 \% \mathrm{Cl}: 7.4354$ to 28.1564); adding a bike rack ( $\beta=14.919,95 \% \mathrm{Cl}: 0.6891$ to 29.1488$)$; and improving access and availability of outdoor activities ( $\beta=15.4671,95 \% \mathrm{Cl}: 5.2029$ to 25.7312) (Hunter et al., 2016). Additionally, changes to the built environment surrounding the school can impact physical activity for children. Ward et al. (2015) analyzed characteristics of 19 Canadian schools to identify specific school features and their influence on physical activity. Active transport was identified as the most favorable school characteristic for promoting different types of physical activity and meeting physical activity recommendations (Ward et al., 2015). These changes, however, cannot be implemented successfully without the appropriate buy-in from the school, students, teachers and broader community. Interventions advocating physical activity and school-based changes need firm basis in behavior change theory, with an ease of implementation and wide appeal for educators (Benjamin Neelon et al., 2016).

\section{CONCLUSION}

Childhood obesity is a result of the imbalance between excessive energy intake and inadequate energy expenditure. A decrease in physical activity in children, accompanied by an increase in sedentary behaviors, threatens to further the childhood obesity epidemic. Disparities between race, sex, and neighborhood environment exist when examining the current state of physical activity in children. The built environment of the neighborhood, including the safety, development and access to public spaces within a neighborhood influences the amount of physical activity and sedentary behavior time in which a child engages. The school environment also contributes an essential component in facilitating physical activity. A better understanding of the factors contributing to the lack of physical activity in children is essential in providing effective policy changes and interventions.

\section{REFERENCES}

Abbott, R. A., Straker, L. M., \& Mathiassen, S. E. (2013). Patterning of children's sedentary time at and away from school. Obesity, 21(1), E131-E133. Doi: https://doi.org/ 10.1002/oby.20127 
Ainsworth, B. E., Haskell, W. L., Leon, A. S., Jacobs, D. R., Jr., Montoye, H. J., Sallis, J. F., \& Paffenbarger, R. S., Jr. (2000). Compendium of physical activities: classification of energy costs of human physical activities. Medicine \& Science in Sports \& Excrcise, 25(1), 71-80. Doi: https://doi.org/10.1249/00005768-199301000-00011

Atkin, A. J., Corder, K., \& van Sluijs, E. M. (2013). Bedroom media, sedentary time and screentime in children: a longitudinal analysis. International Journal of Behavioral Nutrition and Physical Activity, 10. Doi: https://doi.org/10.1186/1479-5868-10-137

Baker, J. L., Olsen, L. W., \& Sorensen, T. I. (2007). Childhood body-mass index and the risk of coronary heart disease in adulthood. The New England Journal of Medicine, 357(23), 2329-2337. Doi: https://doi.org/10.1056/NEJMoa072515

De Beer, M., Hofsteenge, G. H., Koot, H. M., Hirasing, R. A., Delemarre-van de Waal, H. A., \& Gemke, R. J. (2007). Health-related-quality-of-life in obese adolescents is decreased and inversely related to BMI. Acta Paediatrica, 96(5), 710-714. Doi: https://doi.org/10.1111/j.1651-2227.2007.00243.x

Benjamin Neelon, S. E., Mayhew, M., O'Neill, J. R., Neelon, B., Li, F., \& Pate, R. R. (2016). Comparative Evaluation of a South Carolina Policy to Improve Nutrition in Child Care. Journal of the Academy of Nutrition and Dietetics, 116(6), 949-956. Doi: https://doi.org/10.1016/j.jand.2015.10.026

Boone-Heinonen, J., Diez-Roux, A. V., Goff, D. C., Loria, C. M., Kiefe, C. I., Popkin, B. M., \& Gordon-Larsen, P. (2013). The neighborhood energy balance equation: does neighborhood food retail environment + physical activity environment = obesity? The CARDIA study. PLoS One, 8(12), e85141. Doi: https://doi.org/10.1371/ journal.pone.0085141

Brener, N. D., Kann, L., Shanklin, S., Kinchen, S., Eaton, D.K., Hawkins, J., \& Flint, KH.(2013). Methodology of the Youth Risk Behavior Surveillance System--2013. MMWR Recommendations and Reports, 62(1), 1-20. Recuperado de: https://www.cdc.gov/ mmwr/pdf/rr/rr6201.pdf

Broyles, S. T., Myers, C. A., Drazba, K. T., Marker, A. M., Church, T. S., \& Newton, R. L., Jr. (2016). The Influence of Neighborhood Crime on Increases in Physical Activity during a Pilot Physical Activity Intervention in Children. Journal of Urban Health, 93(2), 271-278. Doi: https://doi.org/10.1007/s11524-016-0033-1

Canadian Society for Exercise Physiology. (2016). 24-Hour Movement Guidelines for Children and Youth. Retrieved from http://www.csep.ca/view.asp?x=696

Davis, A. M., Bennett, K. J., Befort, C., \& Nollen, N. (2011). Obesity and related health behaviors among urban and rural children in the United States: data from the National Health And Nutrition Examination Survey 2003-2004 and 2005-2006. Journal of Pediatric Psychology, 36(6), 669-676. Doi: https://doi.org/10.1093/jpepsy/jsq117 
Davis, C. L., Tomporowski, P. D., McDowell, J. E., Austin, B. P., Miller, P. H., Yanasak, N. E., Nathan, E., ...\& Naglieri, J. A. (2011). Exercise improves executive function and achievement and alters brain activation in overweight children: a randomized, controlled trial. Health Psychology, 30(1), 91-98. Doi: https://doi.org/10.1037/a0021766

Deforche, B., De Bourdeaudhuij, I., D'Hondt, E., \& Cardon, G. (2009). Objectively measured physical activity, physical activity related personality and body mass index in 6- to 10-yrold children: a cross-sectional study. International Journal of Behavioral Nutrition and Physical Activity, 6. Doi: https://doi.org/10.1186/1479-5868-6-25

Dobbins, M., Husson, H., DeCorby, K., \& LaRocca, R. L. (2013). School-based physical activity programs for promoting physical activity and fitness in children and adolescents aged 6 to 18. The Cochrane Library, 2 (CD007651). Doi: https://doi.org/10.1002/ 14651858.CD007651.pub2

Eigsti, I., Zayas, V., Mischel, W., Shoda, Y., Ayduk, O., Dadlani, M., Davidson, M., Lawrence, A., Casey, B. (2006). "Predicting cognitive control from preschool to late adolescence and young adulthood." Psychological Science, 17(6), 478-484. Doi: 10.1111/j.14679280.2006.01732.x

Fakhouri, T. H., Hughes, J. P., Brody, D. J., Kit, B. K., \& Ogden, C. L. (2013). Physical activity and screen-time viewing among elementary school-aged children in the United States from 2009 to 2010. JAMA Pediatr, 167(3), 223-229. Doi: https://doi.org/10.1001/2013.jamapediatrics.122

Ferrari, G. L., Araujo, T. L., Oliveira, L., Matsudo, V., Mire, E., Barreira, T. V., Tudor-Locke, C., \& Katzmarzyk, P. T. (2015). Association Between Television Viewing and Physical Activity in 10-Year-Old Brazilian Children. Journal of Physical Activity \& Health, 12(10), 14011408. Doi: https://doi.org/10.1123/ipah.2014-0406

Hallal, P. C., Andersen, L. B., Bull, F. C., Guthold, R., Haskell, W., Ekelund, U., \& Lancet Physical Activity Series Working, G. (2012). Global physical activity levels: surveillance progress, pitfalls, and prospects. The Lancet, 380(9838), 247-257. Doi: https://doi.org/10.1016/S0140-6736(12)60646-1

Harrison, F., \& Jones, A. P. (2012). A framework for understanding school based physical environmental influences on childhood obesity. Health \& Place, 18(3), 639-648. Doi: https://doi.org/10.1016/j.healthplace.2011.12.009

Hill, J. O., Wyatt, H. R., \& Peters, J. C. (2012). Energy balance and obesity. Circulation, 126(1), 126-132. Doi: https://doi.org/10.1161/CIRCULATIONAHA.111.087213

Huberty, J., Dinkel, D., Coleman, J., Beighle, A., \& Apenteng, B. (2012). The role of schools in children's physical activity participation: staff perceptions. Health Education Research, 27(6), 986-995. Doi: https://doi.org/10.1093/her/cys071

Hunter, S., Leatherdale, S. T., Storey, K., \& Carson, V. (2016). A quasi-experimental examination of how school-based physical activity changes impact secondary school -16 - 
student moderate- to vigorous- intensity physical activity over time in the COMPASS study. Internacional Journal of Behavioral Nutrition and Physical Activityt, 13(1). Doi: https://doi.org/10.1186/s12966-016-0411-9

Janssen, I. (2014). Crime and perceptions of safety in the home neighborhood are independently associated with physical activity among 11-15 year olds. Preventive Medicine, 66, 113-117. Doi: https://doi.org/10.1016/j.ypmed.2014.06.016

Kreuser, F., Kromeyer-Hauschild, K., Gollhofer, A., Korsten-Reck, U., \& Rottger, K. (2013). "Obese equals lazy?" analysis of the association between weight status and physical activity in children. Journal of Obesity, 2013. Doi: https://doi.org/10.1155/2013/437017

Laurson, K. R., Lee, J. A., Gentile, D. A., Walsh, D. A., \& Eisenmann, J. C. (2014). Concurrent Associations between Physical Activity, Screen Time, and Sleep Duration with Childhood Obesity. ISRN Obesity, 2014. Doi: https://doi.org/10.1155/2014/204540

LeBlanc, A. G., Katzmarzyk, P. T., Barreira, T. V., Broyles, S. T., Chaput, J. P., Church, T. S., Fogelholm, M., ... \& ISOCLE Research Group. (2015). Correlates of Total Sedentary Time and Screen Time in 9-11 Year-Old Children around the World: The International Study of Childhood Obesity, Lifestyle and the Environment. PLoS One, 10(6), e0129622. Doi: https://doi.org/10.1371/journal.pone.0129622

LeBlanc, A. G., Spence, J. C., Carson, V., Connor Gorber, S., Dillman, C., Janssen, I., Khp, M.E. ... \& Tremblay, M. S. (2012). Systematic review of sedentary behaviour and health indicators in the early years (aged 0-4 years). Applied Physiology, Nutrition, and Metabolism, 37(4), 753-772. Doi: https://doi.org/10.1139/h2012-063

Liang, Y., Hou, D., Zhao, X., Wang, L., Hu, Y., Liu, J., Cheng, H., .. \& Mi, J. (2015). Childhood obesity affects adult metabolic syndrome and diabetes. Endocrine, 50(1), 87-92. Doi: https://doi.org/10.1007/s12020-015-0560-7

Liu, J. H., Jones, S. J., Sun, H., Probst, J. C., Merchant, A. T., \& Cavicchia, P. (2012). Diet, physical activity, and sedentary behaviors as risk factors for childhood obesity: an urban and rural comparison. Childhood Obesity, 8(5), 440-448. Doi: https://doi.org/10.1089/chi.2012.0090

Marietti, M., \& Bugianesi, E. (2016). Obesity: Childhood obesity: time bomb for future burden of chronic liver disease. Nature Reviews Gastroenterology Hepatology, 13, 506-577. Doi: https://doi.org/10.1038/nrgastro.2016.120

Ministerio de Educación Pública (2017). Informe ejecutivo del censo escolar peso/talla, 2016. Primer censo escolar Peso/Talla Costa Rica. [Executive report for the school census on weight/height 2016. First weight/height school census, Costa Rica] Retrieved from http://www.mep.go.cr/sites/default/files/page/adjuntos/informe-ejecutivo-censo-escolarpeso-cortofinal.pdf

Moore, M. M., Robinson, J. C., Rachel, M. M., \& Boss, B. J. (2014). Barriers to physical activity and healthy diet among children ages 6 through 13 in a Mississippi elementary school. 
Journal of Pediatric Nursing, 29(1), 74-82. Doi: https://doi.org/10.1016/i.pedn.2013. $\underline{08.010}$

Morton, K. L., Atkin, A. J., Corder, K., Suhrcke, M., \& van Sluijs, E. M. (2016). The school environment and adolescent physical activity and sedentary behaviour: a mixed-studies systematic review. Obesity Reviews, 17(2), 142-158. Doi: https://doi.org/10.1111/ obr.12352

National Foundation of Sleep. (2018). Children and Sleep. Retrieved from https://sleepfoundation.org/sleep-topics/children-and-sleep

Newton, R. L., Jr., Marker, A. M., Allen, H. R., Machtmes, R., Han, H., Johnson, W. D., Schuna, J., ... \& Church, T. S. (2014). Parent-targeted mobile phone intervention to increase physical activity in sedentary children: randomized pilot trial. JMIR mHealth uHealth, 2(4), e48. Doi: https://doi.org/10.2196/mhealth.3420

Office of Diseade Prevention and Health Promotion. (2016). Health-Related Quality of Life and Well-Being. Retrieved from https://www.healthypeople.gov/2020/about/foundation-healthmeasures/Health-Related-Quality-of-Life-and-Well-Being

Ogden, C. L., Carroll, M. D., \& Flegal, K. M. (2014). Prevalence of obesity in the United States. JAMA, 312(2), 189-190. Doi: https://doi.org/10.1001/jama.2014.6228

Ogden, C. L., Carroll, M. D., Kit, B. K., \& Flegal, K. M. (2014). Prevalence of childhood and adult obesity in the United States, 2011-2012. JAMA, 311(8), 806-814. Doi: https://doi.org/10.1001/jama.2014.732

Owen, C. G., Nightingale, C. M., Rudnicka, A. R., Cook, D. G., Ekelund, U., \& Whincup, P. H. (2009). Ethnic and gender differences in physical activity levels among 9-10-year-old children of white European, South Asian and African-Caribbean origin: the Child Heart Health Study in England (CHASE Study). International Journal of Epidemiology, 38(4), 1082-1093. Doi: https://doi.org/10.1093/ije/dyp176

Pate, R., O'Neill, J., \& Lobelo, F. (2008). The evolving definition of "sedentary". Exercise and Sport Sciences Reviews, 36(4), 173-178. Retrieved from https://www.ncbi.nlm.nih.gov/pubmed/18815485

Puglisi, L. M., Okely, A. D., Pearson, P., \& Vialle, W. (2010). Barriers to increasing physical activity and limiting small screen recreation among obese children. Obesity Research \& Clinic Practice, 4(1), e33-e40. Doi: https://doi.org/10.1016/i.orcp.2009.07.004

Rank, M., Wilks, D. C., Foley, L., Jiang, Y., Langhof, H., Siegrist, M., \& Halle, M. (2014). Healthrelated quality of life and physical activity in children and adolescents 2 years after an inpatient weight-loss program. The Journal of Pediatrics, 165(4), 732-73. Doi: https://doi.org/10.1016/i.jpeds.2014.05.045

Roberts, J. D., Knight, B., Ray, R., \& Saelens, B. E. (2016). Parental perceived built environment measures and active play in Washington DC metropolitan children. 
Preventive Medicine Reports, 3, 373-378. Doi: https://doi.org/10.1016/i.pmedr. $\underline{2016.04 .001}$

Sallis, J. F., Floyd, M. F., Rodriguez, D. A., \& Saelens, B. E. (2012). Role of built environments in physical activity, obesity, and cardiovascular disease. Circulation, 125(5), 729-737. Doi: https://doi.org/10.1161/CIRCULATIONAHA.110.969022

Schwimmer, J. B., Burwinkle, T. M., \& Varni, J. W. (2003). Health-related quality of life of severely obese children and adolescents. JAMA, 289(14), 1813-1819. Doi: https://doi.org/10.1001/jama.289.14.1813

Scott, H., Tyton, T., \& Horswill, C.(2016). OCCUPATIONAL SEDENTARY BEHAVIOR AND SOLUTIONS TO INCREASE NON-EXERCISE ACTIVITY THERMOGENESIS. Pensar en Movimiento: Revista de Ciencias del Ejercicio y la Salud, 14 (2), 1 - 21. Doi: http://dx.doi.org/10.15517/pensarmov.v14i2.23644

Stevens, S. D., Herbozo, S., Morrell, H. E., Schaefer, L. M., \& Thompson, J. K. (2016). Adult and childhood weight influence body image and depression through weight stigmatization. Journal of Health Psycolohy, 22 (8), 1084-1093. Doi: https://doi.org/10.1177/ 1359105315624749

Tappe, K. A., Glanz, K., Sallis, J. F., Zhou, C., \& Saelens, B. E. (2013). Children's physical activity and parents' perception of the neighborhood environment: neighborhood impact on kids study. International Journal of Behavioral Nutrition and Phsycal Activity, 10. Doi: https://doi.org/10.1186/1479-5868-10-39

Tremblay, M.S., Aubert, S., Barnes, J.D., Carson, V., Latimer-Cheung, A.E., Chastin, S.F.M.m Teatske, M.A., Chinapaw, M.J.M \& SBRN Terminology Consensus Project Participants. (2017). Sedentary Behavior Research Network (SRBN) - Terminology Consensus Project process and outcome. International Journal Nutrition Physical Activity, 14(1), 1-17. Retrieved from https://www.ncbi.nlm.nih.gov/pubmed/28599680

U.S. Department of Health and Human Services. (2008). 2008 Physical Activity Guidelines for Americans. Retrieved from https://health.gov/paguidelines/pdf/paguide.pdf

Wafa, S. W., Shahril, M. R., Ahmad, A. B., Zainuddin, L. R., Ismail, K. F., Aung, M. M., \& Mohd Yusoff, N. A. (2016). Association between physical activity and health-related quality of life in children: a cross-sectional study. Health and Quality of life Outcomes, 14(1). Doi: https://doi.org/10.1186/s12955-016-0474-y

Ward, S., Belanger, M., Donovan, D., Caissie, I., Goguen, J., \& Vanasse, A. (2015). Association Between School Policies and Built Environment, and Youth's Participation in Various Types of Physical Activities. Journal of School Health, 85(7), 423-432. Doi: https://doi.org/10.1111/josh.12273

Watson, K. B., Harris, C. D., Carlson, S. A., Dorn, J. M., \& Fulton, J. E. (2016). Disparities in Adolescents' Residence in Neighborhoods Supportive of Physical Activity - United States, 
2011-2012. Morbity and Mortality Weekly Report (MMWR), 65(23), 598-601. Doi: https://doi.org/10.15585/mmwr.mm6523a2

World Health Organization. (2010). Global Recommendations on Physical Activity. Switzerland: WHO Press. Retrieved from http://www.who.int/dietphysicalactivity/publications/ 9789241599979/en/

Contribution: A- Funding, B- Study design, C- Data collection, D- Statistical analysis and interpretation of results, E- Manuscript preparation. 